\title{
Nota de lectura
}

CAZETTA, Felipe. Fascismos (?): análises do integralismo lusitano e da ação integralista brasileira (1914-1937). 1. ed. Jundiaí: Paco editorial, 2019.

Jordi Estivill ${ }^{1}$

En la amplíssima literatura dedicada al anàlisis del fascismo, no faltan los trabajos comparativos. A título de ejemplo pueden citarse a Linz, Poulantzas, Nolte. Payne, Levy, Felice y se puede recordar que uno de los primeros congresos, después de la revolución de los claveles, que reunieron a los historiadores portugueses en $1986^{2}$, recibió las contribuciones de sus colegas (Woolf, Payne, Tusell, Paxton, Gentile, Fischer.Galati. Kühnl....) de otros países que precisamente se habían dedicado a esta labor comparativa. Pero, salvo alguna excepción ${ }^{3}$ no abundan las investigaciones que contrastan la evolución del ideario fascista entre Europa y América Latina, y aún menos, estrictamente entre Brasil y Portugal. Por lo tanto, esta ausencia que ahora queda cubierta, sería una primera razón para poner de relieve el valor de la obra de Felipe Acevedo Cazetta.

Una segunda razón para resaltar este trabajo es que el realizar esta comparación, permite iluminar con mayor intensidad determinados aspectos, que si solo se hiciera un examen nacional no saldrían a la luz. Una tercera razón es la coherencia y el rigor de este libro que es el resultado adaptado de una tesis presentada en el año 2016.

El autor de este libro acierta con su título "Fascismos", por cuanto como más se profundiza en el análisis del fascismo más se descubre que, sobre un fondo comùn, aparece su carácter heteróclito. Así cada vez está más claro que hubo variadas expresiones fascistas influenciadas por las evoluciones económicas, sociales, políticas y culturales de cada estado, que aun dentro de un mismo país, estas expresiones tenían connotaciones diversas y que fueron

\footnotetext{
${ }^{1}$ Universidade de Barcelona - Espanha. E-mail: jordi_estivill@ hotmail.com.

2 AA.VV. (1987) O estado Novo. Das origens ao fim da dictadura. 1926-1959. Lisboa Ed. Fragmentos. II Vol.

${ }^{3}$ Larsen, S.U. (Ed.) (2001). Fascism outside europe. N.Y. Columbia University Press.
} 
adaptando su discurso en las diferentes fases que vivieron. Este es el caso del integralismo lusitano y de su correspondiente brasileño. No solo hubo organizaciones diversas sino dentro de ellas, discursos relativamente heterogéneos, que de todos modos alimentaban un tronco común. Descubrir este tronco común y al mismo tiempo ser sensible a las diferencias no es tarea fácil. Esto es lo que hace esta publicación.

Esta característica se pone de manifiesto en este libro por cuanto su principal óptica es la de hacer un análisis teórico doctrinario de los fascismos brasileño y portugués y ver cuales son sus principales similitudes y diferencias y sus mutuas influencias. Para concretar este objetivo, el autor recorre a explicar sintéticamente las biografías de los principales líderes, a estudiar detalladamente sus discursos y publicaciones y a rastrear las referencias que se hacían mutuamente, en sus periódicos y revistas, donde destacan Naçao Portuguesa y América Brasileira.

Viajes, contactos, noticias, artículos compartidos y alabanzas mutuas prueban que el Integralismo Lusitano y el Nacional Sindicalismo de este país no estaban tan lejos de la Acçao Integralista Brasileira y aun de la Acçao Imperial Patrianovista Brasileira. Durante un cierto tiempo bebían unos de otros y encontraban una común inspiración en Maurras y el corporativismo que la Iglesia católica preconizaba desde la encíclica Rerum Novarum y que la Qudragesimo Anno de Pio XII reafirmó en 1931. También admiraban los avances de Mussolini en Italia. En cambio, no deja de ser sorprendente que casi no se encuentren referencias a los autores y líderes fascistas españoles o al rumano Manoilescu que fue uno de los divulgadores del corporativismo más conocido en Europa en los años treinta. Parece evidente que la lusofonia y un pasado comùn entre Brasil y Portugal debió jugar un positivo y contradictorio papel entre aquellos movimientos.

Contradictorio, porque la afirmación nacionalista y su fijación por reconstruir la historia, propias de estas posiciones, les llevaban a ensalzar la época imperial de Portugal y su dominio sobre Brasil. De ahí que como Cazetta ilustra, algunos líderes brasileiros oscilasen entre la lusofilia y la lusofobia. Pudo más la primera y por lo que parece las relaciones fueron estrechas y positivas. Queda por ahora sin responder la pregunta de hasta que punto estas relaciones fueron favorecidas por los emigrantes portugueses en Brasil y por la propaganda que el Estado Novo hacía en este país ${ }^{4}$. De todos modos, ¿que tenían en común los integralismos brasileño y portugués y sus líderes?

\footnotetext{
${ }^{4}$ Paulo.E. (2000 ) Aquí tambem é Portugal: a colónia portuguesa no Brasil e o Salazarismo. Coimbra, Quarteto.
} 
En primer lugar, según Cazetta, comparten un pasado literario y hasta cierto punto elitista. Hubiera sido interesante profundizar en el primero ya que el modernismo ${ }^{5}$ artístico y literario fue predominante en aquella época y hubiera podido dar algunas claves para entender mejor los origenes culturales de aquellos líderes y de sus expresiones fascistas. No deja de ser curioso que algunos de ellos compartan estudios jurìdicos en las facultades de derecho de Coïmbra y de Recife y Sao Paulo y que allí se forme una identidad de grupo. En el caso portuguès no deja de ser sorprendente que autores tan diferentes como Herculano, Garrett y Antero de Quental sean los referentes anteriores del naciente integralismo.

En segundo lugar, ambos movimientos comparten su crítica al liberalismo y a los regímenes parlamentarios a los que adjudican todos los males históricos y reaccionan contra el comunismo. Dios. Patria y Familia podría ser el lema que les une en una concepción tradicionalista que tratan de justificar con una visión histórica peculiar que ellos reconstruyen a su manera. Esta visión les lleva hasta la época medieval en la que florecían organicismo y corporativismo, que constituyen sus fundamentos organizativos para la sociedad que se proponen construir. Un estado fuerte, con ansias expansionistas y centralizado políticamente, pero que otorga poderes administrativos a los municipios les parece ser la mejor fórmula de gobierno. Monárquicos convencidos en su origen, algunos aceptan un cierto republicanismo que no caiga en los defectos de las denunciadas constituciones de 1891 en Brasil y del régimen republicano portugués de 1910.

La descripción de estas características es una parte muy substantiva de este libro, que a veces se hace repetitiva como cuando se alarga la presentación del ideario Maurrasiano. Era casi inevitable, ya que, a pesar de pequeñas matizaciones ligadas a itinerarios personales, las expresiones doctrinarias de estas dos corrientes fascistas se parecen y no brillan por su originalidad. Quizás, hubiera sido útil dedicar más espacio a explicar su articulación con el contexto cronológico y politico de cada país. Esto hubiera facilitado la tarea de los potenciales lectores de los dos países. Los brasileños no conocen muy bien la evolución política de Portugal de después de la primera guerra mundial y al revés, no muchos portugueses saben las vicisitudes de la vida política brasileña.

Igualmente, si se hubiesen caracterizado mejor a las organizaciones (fuerza, afiliados, modos de organización interna, actividades externas, ...) se habría podido pasar a otros niveles

\footnotetext{
${ }^{5}$ Griffin,R. (2003) Modernism anf fascism. The sense of a beguining under Mussolini and Hitler. N.Y. Palgrave. Mac-Millan.
} 
de interpretación ${ }^{6}$. Pero esto se escapa a los objetivos del trabajo. El cual hace avanzar en el conocimiento de dos movimientos protofacistas en sus inicios y más declaradamente fascistas en sus respectivas maduraciones, en dos países, tan lejanos y cercanos, como Brasil Y Portugal. Igualmente contribuye a comprender mejor sus relaciones y mutuas influencias, Abre así un estimulante campo, relativamente inexplorado, que hay que esperar sea cultivado por otros investigadores. En cualquier caso, permite sugerir que las expresiones fascistas en Brasil, como en el caso de Mejico $^{7}$, no fueron meras copias o mimetismos de lo que sucedía en Europa. Tuvieron sus rasgos específicos. En este sentido, con esta publicación, se da un paso adelante con respecto a las consideraciones que formulaba Helgio Trindade ${ }^{8}$ hace casi cuarenta años atrás.

Por fin, para finalizar esta nota de lectura hay que constatar como lo hace Felipe Cazetta que en los últimos tiempos los movimientos y las posiciones de extrema derecha han aumentado no solo en su presencia en gobiernos y administraciones en todo el mundo sino también en las practicas cotidianas de muchos ciudadanos y compartir con el, su preocupación por este crecimiento. Conocer mejor sus origenes y despliegues ideológicos se convierte así en una manera de empezar a combatirlo. Es lo que hace este libro que ahora se recomienda.

\footnotetext{
${ }^{6}$ Para una interpretación comparativa de las politicas sociales de los fascismos en Portugal, Itàlia, España y Alemania ver Estivill. J. (2020) Europa nas trevas. As politicas sociais nos fascismos. Lisboa Universidad Nova de Lisboa.

${ }^{7}$ Meyer, J. (1977) Le sinarquisme: Un mouvement fasciste Mexicain. Paris. Ed. Hachette.

8 Trindade, H.(1982) El tema del fascismo en America Latina, Revista de Estudios Politicos n. 50.
} 